\title{
Correction to: Globalizing Gramsci: The Resuscitation of a Repressed Intellectual
}

\section{Marco Santoro, Andrea Gallelli and Matteo Gerli}

\section{Correction to:}

Chapter 8 in: G. Sapiro et al. (eds.), Ideas on the Move in the Social Sciences and Humanities, Socio-Historical Studies of the Social and Human Sciences, https://doi.org/10.1007/978-3-030-35024-6_8

The original version of the chapter was revised: The Figure 8.4 has been replaced with an updated version of the figure. 


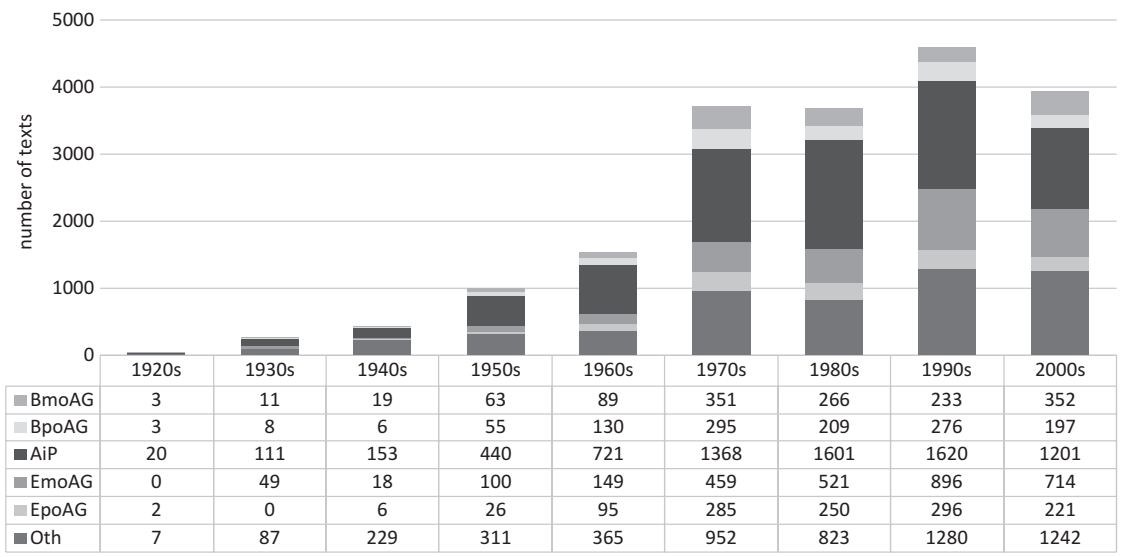

Fig. 8.4 The production of Gramscian literature by decade and document type. BmoAG Books mainly on AG; BpoAG Books partly on AG; AiP Articles in periodicals; EmoAG Essays in books mainly on AG; EpoAG Essays in books partly on AG; Oth Other. (Source: Elaboration on GB file; Note: 19,608 documents; 424 missing data) 